\title{
Development and validation of a prognostic nomogram for IgA nephropathy
}

\author{
Jian Liu ${ }^{1 *}$, Shuwei Duan ${ }^{1, *}$, Pu Chen ${ }^{1}$, Guangyan Cai ${ }^{1}$, Yong Wang ${ }^{1}$, Li Tang ${ }^{1}$, Shuwen \\ Liu $^{1}$, Jianhui Zhou ${ }^{1}$, Di Wu ${ }^{1}$, Wanjun Shen ${ }^{1}$, Xiangmei Chen ${ }^{1}$ and Jie Wu${ }^{1}$ \\ ${ }^{1}$ Department of Nephrology, Chinese People's Liberation Army (PLA) General Hospital, Chinese PLA Institute of Nephrology, \\ State Key Laboratory of Kidney Diseases, National Clinical Research Center for Kidney Diseases, Beijing Key Laboratory of \\ Kidney Diseases, Beijing, China \\ *These authors have contributed equally to this work \\ Correspondence to: Xiangmei Chen, email: xmchen301@126.com \\ Jie Wu, email: wujie301@126.com \\ Keywords: nomogram, IgA nephropathy, prognosis, pathology, risk \\ Received: July 06, $2017 \quad$ Accepted: August 27, $2017 \quad$ Published: October 10, 2017 \\ Copyright: Liu et al. This is an open-access article distributed under the terms of the Creative Commons Attribution License 3.0 \\ (CC BY 3.0), which permits unrestricted use, distribution, and reproduction in any medium, provided the original author and source \\ are credited.
}

\section{ABSTRACT}

IgA nephropathy (IgAN) shows strong heterogeneity between individuals. IgAN prognosis is associated with pathological lesions and clinical indicators. However, simple tools for evaluating the clinical prognosis remain inadequate. Our objective was to develop an intuitive estimation tool for predicting the IgAN prognosis. 349 patients with IgAN at The Chinese People's Liberation Army General Hospital were retrospectively analyzed from data between 2000 and 2006. A nomogram was developed using COX regression coefficients to predict decline of estimate Glomerular filtration rate (eGFR) $\geq 50 \%$ and end-stage renal disease (ESRD). The discriminative ability and predictive accuracy of the nomogram was determined via concordance index ( $\mathrm{C}$-index) and calibration curve. The results were verified in an independent validation cohort. In the derivation cohort, the nomogram was developed using mesangial hypercellularity, tubular atrophy/interstitial fibrosis, average proteinuria (A-P), and average mean arterial pressure (A-MAP) during hospitalization. The C-index of the nomogram was 0.88 ( $95 \%$ CI, 0.80 to 0.96 ). The calibration curve showed good agreement between prediction and actual observation. Furthermore, the nomogram demonstrated good discrimination ( $\mathrm{C}$-index $=0.87,95 \% \mathrm{CI} 0.78$ to 0.95 ) and calibration in the validation cohort. The nomogram could predict the prognosis of IgAN effectively and intuitively.

\section{INTRODUCTION}

IgA nephropathy (IgAN) is the most prevalent primary glomerulonephritis worldwide. IgAN is characterized by mesangial deposition of polymeric IgA1. Although IgA nephropathy progresses relatively slowly, the prognosis differs quite significantly among different individuals; therefore, a more refined prognostic evaluation has been the focus of researchers. The prognosis of $\operatorname{IgA}$ nephropathy is associated with risk factors [1] including pathological and clinical indicators. The Lee grade [2] and the Haas grade [3] are widely used pathological staging systems in clinics. In recent years, the Oxford classification [4] was added to the list, including mesangial hypercellularity $(\mathrm{M})$, endocapillary proliferation (E), segmental sclerosis (S), tubular atrophy/ interstitial fibrosis (T), and crescent [5] (C). However, the risk of end-stage renal disease (ESRD) cannot be easily and directly evaluated via these staging systems. For example, it remains uncertain whether a patient with Oxford M0T0S1E1C1 will progress to ESRD after five years. Thus, the Oxford classification is more suitable to analyze prognostic risk factors for a group of patients than calculating individual risks. However, some clinical 
indicators, such as proteinuria [6-9], hypertension [10], and estimated glomerular filtration rate (eGFR), have also prognostic value $[11,12]$. The aim of this study was to establish a tool to predict the outcomes of IgAN using clinical and pathological indicators.

\section{RESULTS}

\section{Baseline characteristics and endpoints of patients}

604 participants were enrolled in this study. In the derivation cohort, 349 patients with IgA nephropathy met the inclusion criteria and were entered into this study. In the validation cohort, 255 patients met the inclusion criteria. Baseline data and endpoints are listed in Table 1. The median follow-up was conducted after 84 months and 76.8 months in the derivation and validation cohort, respectively. Endpoint events during the follow-up were 64 and 32 in the derivation and validation cohort, respectively. Four patients who died without endpoints were defined as right-censored data. The causes of death were myocardial infarction $(\mathrm{n}=1)$, acute cerebral infarction $(n=1)$, gastrointestinal hemorrhage $(n=1)$, and unknown disease $(\mathrm{n}=1)$. In the derivation cohort, the 5-, 8 -, and 10 -year renal survival rates were $95.0 \%, 76.1 \%$, and $63.9 \%$, respectively. In the validation cohort, the 5-, 8 -, and 10 -year renal survival rates were $94.8 \%, 75.2 \%$, and $61.3 \%$, respectively.

\section{Independent prognostic factors in the primary cohort}

A univariate COX regression analysis was performed using pathological indicators $(\mathrm{M} / \mathrm{E} / \mathrm{S} / \mathrm{T} / \mathrm{C})$, clinical indicators (sex, age, proteinuria, mean arterial pressure, and eGFR), and treatment indicators (use of, glucocorticoids or immunosuppressive agents, ACEI/ ARB). All variables are listed in Table 2. The results showed that variables with $\mathrm{P}<0.05$ included $\mathrm{M}, \mathrm{S}, \mathrm{T}$, average proteinuria during hospitalization (A-P), average mean arterial pressure (A-MAP), eGFR $<30 \mathrm{~mL} / \mathrm{min}$ per $1.73 \mathrm{~m}^{2}$, and use of glucocorticoids or immunosuppressive agents. In the multivariate analysis with backward stepwise, two pathologic measures ( $\mathrm{M}$ and $\mathrm{T}$ ) and two clinical variables (A-P and A-MAP) were selected as independent risk factors for endpoints.

\section{Prognostic nomogram based on COX regression to predict renal survival}

A nomogram (Figure 1) to predict renal survival was developed using results from multivariate COX regression. Points were assigned to the four identified factors according to their regression coefficients. For each patient, the accumulated total points were compared to the survival scale to evaluate renal survival in different years. The concordance index (C-index) for the nomogram was 0.88 (95\% confidence interval, 0.80 to 0.96$)$. The calibration plot for the probability of survival at 5,8 , and 10 years after biopsy showed optimal agreement between the prediction via nomogram and the actual observation (Figure 2).

\section{Predictive accuracy of nomogram and other conventional classification systems in the derivation cohort}

As shown in Figure 3, Lee grade [2] and Haas grade [3] showed good prognostic stratification for patients between stage III and stage IV or later in both cohorts. However, in both cohorts, both Lee grade and Haas grade were unsatisfactory in stratifying patients between stages I and II. The mesangial hypercellularity (M0/M1), segmental sclerosis $(\mathrm{S} 0 / \mathrm{S} 1)$, and tubular atrophy/interstitial fibrosis (T0/T1/T2) of the Oxford classification showed good prognostic stratification for patients. However, crescent $(\mathrm{C} 0 / \mathrm{C} 1 / \mathrm{C} 2)$ and endocapillary proliferation (E0/E1) were not as good as the other three indicators of the Oxford classification in distinguishing patients of both cohorts (Figure 3).

The $\mathrm{C}$-index of the nomogram was 0.88 . The calibration curve (Figure 2) of the nomogram showed good agreement between prediction and observation. These results suggest that our nomogram displayed good accuracy in predicting renal survival in the derivation cohort. In the same cohort, the C-index of the Lee grade, Haas grade, and Oxford Classification were $0.76,0.74$, and 0.78 , respectively (Table 3 ). The nomogram seemed to have a higher C-index; however, the statistical difference between the nomogram and the other classification systems must be calculated in the validation cohort.

\section{Comparison of predictive accuracy for renal survival between nomogram and other conventional classification systems in the validation cohort}

In the validation cohort, the $\mathrm{C}$-index of the nomogram was 0.87 (Table 4), which was higher than the Oxford classification (0.79), the Lee grade (0.77) [2], and the Hass grade [3] (0.74), $(\mathrm{p}<0.01)$. The calibration curve (Figure 2) of the nomogram showed good agreement between prediction and observation in the probability of 5-year, 8-year, and 10-year renal survival.

\section{DISCUSSION}

In this study, we developed and validated a nomogram, consisting of four variables: A-proteinuria; A-MAP; Mesangial hypercellularity (M), and tubular atrophy/interstitial fibrosis $(\mathrm{T})$. To select prognostic 
Table 1: Baseline characteristics of the patients in the derivation and validation cohorts

\begin{tabular}{|c|c|c|c|}
\hline & Modeling $(n=349)$ & Validation $(n=255)$ & P value \\
\hline $\operatorname{Sex}(M / F)$ & $189 / 160$ & $126 / 129$ & 0.28 \\
\hline Age (year) & $35.42 \pm 9.53$ & $35.42 \pm 10.10$ & 0.99 \\
\hline eGFR(No. of patients) & & & 0.15 \\
\hline$>90 \mathrm{ml} / \mathrm{min} / 1.73 \mathrm{~m}^{2}$ & 213 & 170 & \\
\hline $60-90 \mathrm{ml} / \mathrm{min} / 1.73 \mathrm{~m}^{2}$ & 97 & 62 & \\
\hline $30-60 \mathrm{ml} / \mathrm{min} / 1.73 \mathrm{~m}^{2}$ & 18 & 10 & \\
\hline$<30 \mathrm{ml} / \mathrm{min} / 1.73 \mathrm{~m}^{2}$ & 21 & 13 & \\
\hline A-P(No. of patients) & & & 0.32 \\
\hline$<0.5 \mathrm{~g} / 24 \mathrm{~h}$ & 128 & 88 & \\
\hline $0.5-1 \mathrm{~g} / 24 \mathrm{~h}$ & 108 & 107 & \\
\hline $1-3.5 \mathrm{~g} / 24 \mathrm{~h}$ & 85 & 48 & \\
\hline$>3.5 \mathrm{~g} / 24 \mathrm{~h}$ & 28 & 12 & \\
\hline A-MAP(mmHg) & $91.71 \pm 11.91$ & $93.14 \pm 11.46$ & 0.09 \\
\hline \multicolumn{4}{|l|}{ Oxford classification(No. of patients) } \\
\hline $\mathrm{M}(\mathrm{M} 0 / \mathrm{M} 1)$ & $237 / 112$ & $159 / 96$ & 0.17 \\
\hline $\mathrm{E}(\mathrm{E} 0 / \mathrm{E} 1)$ & $302 / 47$ & $237 / 18$ & $<0.01$ \\
\hline $\mathrm{S}(\mathrm{S} 0 / \mathrm{S} 1)$ & $100 / 249$ & $75 / 180$ & 0.86 \\
\hline $\mathrm{T}(\mathrm{T} 0 / \mathrm{T} 1 / \mathrm{T} 2)$ & $115 / 170 / 64$ & $105 / 108 / 42$ & 0.07 \\
\hline $\mathrm{C}(\mathrm{C} 0 / \mathrm{C} 1 / \mathrm{C} 2)$ & $288 / 60 / 1$ & $213 / 41 / 1$ & 0.83 \\
\hline $\begin{array}{l}\text { Application of glucocorticoids or } \\
\text { immunosuppressive agents (No/Yes) }\end{array}$ & $196 / 153$ & $147 / 108$ & 0.74 \\
\hline ARB or ACEI (No/Yes) & $54 / 295$ & $34 / 221$ & 0.486 \\
\hline endpoint(No/Yes) & $285 / 64$ & $223 / 32$ & 0.06 \\
\hline
\end{tabular}

factors, Oxford $\mathrm{M} / \mathrm{E} / \mathrm{S} / \mathrm{T} / \mathrm{C}$ was not completely necessary after adjustment for clinical indicators. Other studies also support our result. Based on a Chinese population, Zeng et al. [31] conducted a multicenter study, enrolling 1,026 patients, and only $\mathrm{M} / \mathrm{T}$ lesions were related to the prognosis of patients via multivariate analysis. Coppo et al. [32] reported a multicenter retrospective Europeanbased VALIGA cohort study that comprised 1,147 IgAN patients. The results of their study were similar in so far that only the $\mathrm{M} / \mathrm{T}$ lesions were found to be associated with the prognosis of patients using multivariate analysis. However, clinical indicators, such as baseline proteinuria, baseline blood pressure, and baseline eGFR were acknowledged as prognostic factors [33, 34]. However, clinical indicators always fluctuated and may be affected during a short time by treatment. Thus, we calculated the average mean arterial pressure and the average proteinuria during hospitalization instead of a one-time measurement, which enhanced the stability of these indicators.
Comparing the total points in the nomogram with the risk scale, we could comprehensively evaluate renal survival at different time points for each patient. The nomogram showed good discriminations for renal survival. The calibration curves exhibited a good fit with the observed incidence rate of renal survival in both the derivation and the validation cohorts for different years. Furthermore, the nomogram had a statistically improved accuracy in predicting renal survival compared to the pathological staging systems widely used in clinics such as the Lee grade, the Haas grade, and the Oxford classification. These results suggest that our nomogram is accurate for predicting long-term renal survival among Chinese IgAN patients.

In addition to commonly used pathological staging systems, some score systems to predict outcome of IgAN have been previously reported. However, these studies had several limitations. Berthoux et al. developed a risk score from data of 332 French patients [35], but their score evaluated histologic lesions using their own original 
Table 2: Univariate and multivariate $\mathrm{COX}$ regression analysis

\begin{tabular}{|c|c|c|c|c|c|c|c|c|}
\hline & \multicolumn{4}{|c|}{ Univariate } & \multicolumn{4}{|c|}{ Multivariate $^{\mathrm{a}}$} \\
\hline & patients & $\begin{array}{c}\text { End } \\
\text { points }\end{array}$ & HR & $95.0 \% \mathrm{CI}$ & $\mathbf{P}$ & HR & $95.0 \% \mathrm{CI}$ & P value \\
\hline \multicolumn{9}{|l|}{ Sex } \\
\hline women & 160 & 28 & $\begin{array}{c}1.00 \\
\text { (reference) }\end{array}$ & & & NS & & \\
\hline men & 189 & 36 & 0.82 & $0.49-1.35$ & 0.82 & & & \\
\hline Age & & & 1.11 & $0.99-1.04$ & 0.20 & NS & & \\
\hline \multicolumn{9}{|l|}{ eGFR } \\
\hline$>90 \mathrm{ml} / \mathrm{min} / 1.73 \mathrm{~m}^{2}$ & 213 & 25 & $\begin{array}{c}1.00 \\
\text { (reference) }\end{array}$ & & & NS & & \\
\hline $60-90 \mathrm{ml} / \mathrm{min} / 1.73 \mathrm{~m}^{2}$ & 97 & 21 & 1.71 & $0.72-4.10$ & 0.21 & & & \\
\hline $30-60 \mathrm{ml} / \mathrm{min} / 1.73 \mathrm{~m}^{2}$ & 18 & 6 & 3.08 & $0.88-10.84$ & 0.04 & & & \\
\hline$<30 \mathrm{ml} / \mathrm{min} / 1.73 \mathrm{~m}^{2}$ & 21 & 12 & 5.88 & $2.30-14.99$ & $<0.01$ & & & \\
\hline \multicolumn{9}{|l|}{ A-P } \\
\hline$<0.5 \mathrm{~g} / 24 \mathrm{~h}$ & 128 & 8 & $\begin{array}{c}1.00 \\
\text { (reference) }\end{array}$ & & & 1.00 (reference) & & \\
\hline $0.5-1 \mathrm{~g} / 24 \mathrm{~h}$ & 108 & 18 & 2.23 & $1.70-2.91$ & 0.05 & 1.49 & $1.08-2.04$ & 0.01 \\
\hline $1-3.5 \mathrm{~g} / 24 \mathrm{~h}$ & 85 & 29 & 4.95 & $2.23-10.79$ & $<0.01$ & 2.23 & $1.24-3.64$ & $<0.01$ \\
\hline$>3.5 \mathrm{~g} / 24 \mathrm{~h}$ & 28 & 9 & 11.02 & $3.25-22.47$ & $<0.01$ & 3.32 & $1.96-5.01$ & $<0.01$ \\
\hline A-MAP & & & 1.04 & $1.02-1.06$ & $<0.01$ & 1.03 & $1.01-1.05$ & $<0.01$ \\
\hline \multicolumn{9}{|l|}{ Oxford classification } \\
\hline \multicolumn{9}{|l|}{$\begin{array}{l}\text { Mesangial } \\
\text { hypercellularity }\end{array}$} \\
\hline M0 & 237 & 20 & $\begin{array}{c}1.00 \\
\text { (reference) }\end{array}$ & & & 1.00 & (reference) & \\
\hline M1 & 112 & 44 & 4.73 & $2.78-8.04$ & $<0.01$ & 1.80 & $1.00-3.29$ & 0.05 \\
\hline \multicolumn{9}{|l|}{$\begin{array}{l}\text { Endocapillary } \\
\text { hypercellularity }\end{array}$} \\
\hline E0 & 302 & 56 & $\begin{array}{c}1.00 \\
\text { (reference) }\end{array}$ & & & NS & & \\
\hline E1 & 47 & 8 & 1.26 & $0.59-2.67$ & 0.55 & & & \\
\hline \multicolumn{9}{|l|}{$\begin{array}{l}\text { Segmental } \\
\text { glomerulosclerosis }\end{array}$} \\
\hline S0 & 100 & 7 & $\begin{array}{c}1.00 \\
\text { (reference) }\end{array}$ & & & NS & & \\
\hline $\mathrm{S} 1$ & 249 & 57 & 3.368 & $1.54-7.40$ & $<0.01$ & & & \\
\hline \multicolumn{9}{|l|}{$\begin{array}{l}\text { interstitial tubular } \\
\text { atrophy/interstitial } \\
\text { fibrosis }\end{array}$} \\
\hline T0 & 115 & 8 & $\begin{array}{c}1.00 \\
\text { (reference) }\end{array}$ & & & $1.00($ reference $)$ & & \\
\hline $\mathrm{T} 1$ & 170 & 22 & 3.77 & $1.41-10.07$ & $<0.01$ & 3.818 & $1.37-10.65$ & 0.01 \\
\hline
\end{tabular}




\begin{tabular}{|c|c|c|c|c|c|c|c|c|}
\hline & \multicolumn{4}{|c|}{ Univariate } & \multicolumn{4}{|c|}{ Multivariate $^{a}$} \\
\hline & patients & $\begin{array}{c}\text { End } \\
\text { points }\end{array}$ & HR & $95.0 \% \mathrm{CI}$ & $\mathbf{P}$ & HR & $95.0 \% \mathrm{CI}$ & P value \\
\hline $\mathrm{T} 2$ & 64 & 34 & 23.70 & $9.01-62.30$ & $<0.01$ & 16.30 & $5.75-46.20$ & $<0.01$ \\
\hline \multicolumn{9}{|c|}{$\begin{array}{l}\text { Cellular or fabrocellular } \\
\text { Crescent }\end{array}$} \\
\hline $\mathrm{C} 0$ & 288 & 49 & $\begin{array}{c}1.00 \\
\text { (reference) }\end{array}$ & & & NS & & \\
\hline $\mathrm{C} 1+\mathrm{C} 2$ & 61 & 15 & 1.88 & $1.05-3.37$ & 0.03 & & & \\
\hline \multicolumn{9}{|c|}{ Use of GC or IS } \\
\hline no & 196 & 27 & $\begin{array}{c}1.00 \\
\text { (reference) }\end{array}$ & & & NS & & \\
\hline yes & 153 & 37 & 2.19 & $1.31-3.68$ & 0.03 & & & \\
\hline \multicolumn{9}{|c|}{ Use of ARB or ACEI } \\
\hline no & 54 & 6 & $\begin{array}{c}1.00 \\
\text { (reference) }\end{array}$ & & & NS & & \\
\hline yes & 295 & 58 & 1.59 & $0.68-3.70$ & 0.28 & & & \\
\hline
\end{tabular}

$\mathrm{HR}$, hazard ratio; CI, confidence interval; A-P, average proteinuria; A-MAP, average mean arterial pressure; GC or IS, glucocorticoids or immunosuppressive agents; NS, not selected.

${ }^{a}$ Variables were selected by using a Cox proportional hazard model and a stepwise backward method.
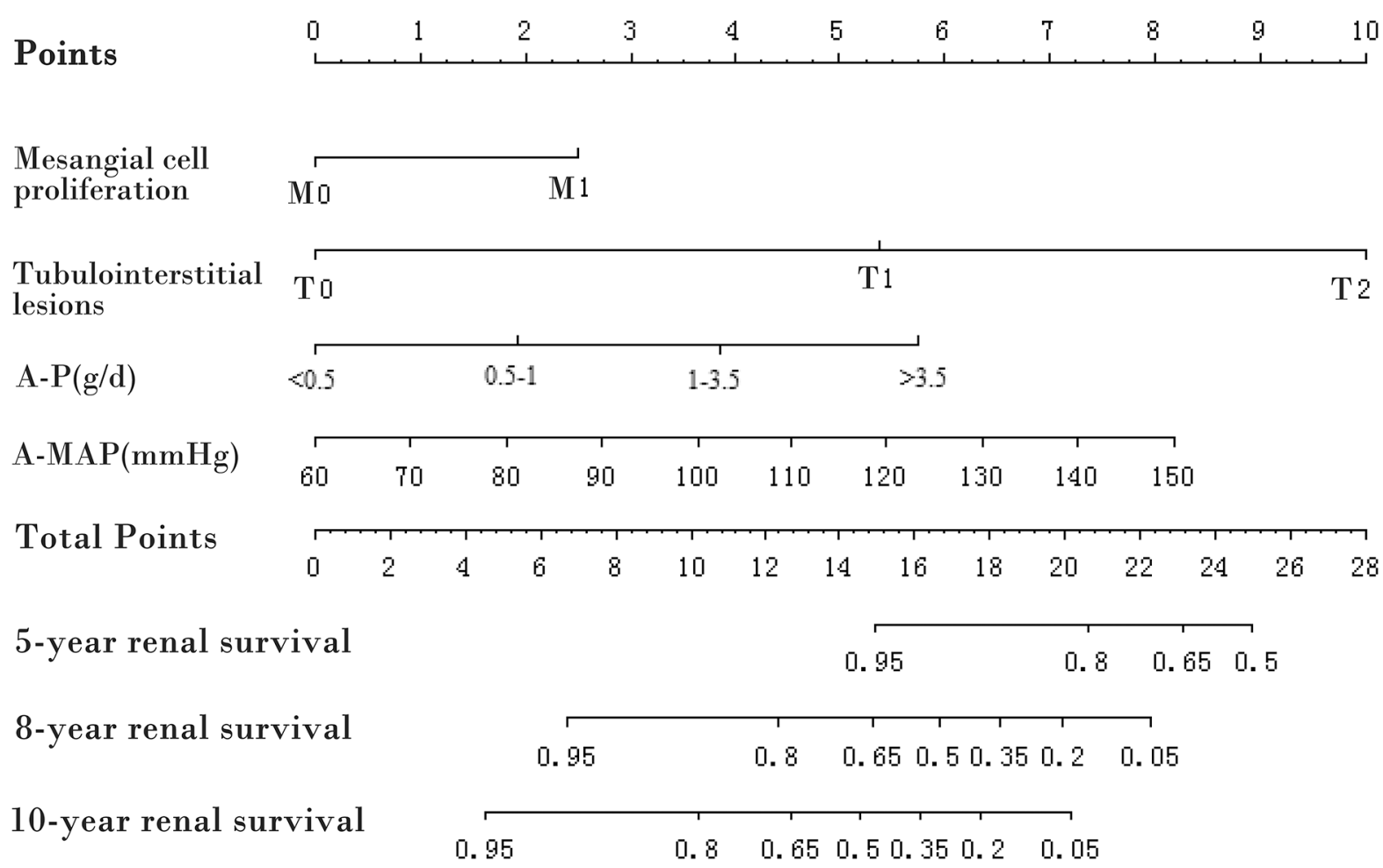

Figure 1: Prognostic nomogram. A-P, average proteinuria; A-MAP, average mean arterial pressure. To use the nomogram, draw a line perpendicular from the corresponding axis of each risk factor until it reaches the top line labeled "Points." Sum up the number of points for all risk factors then draw a line descending from the axis labeled "Total points" until it intercepts each of the survival axes to determine 5-, 8-, and 10-year survival probabilities. 
A

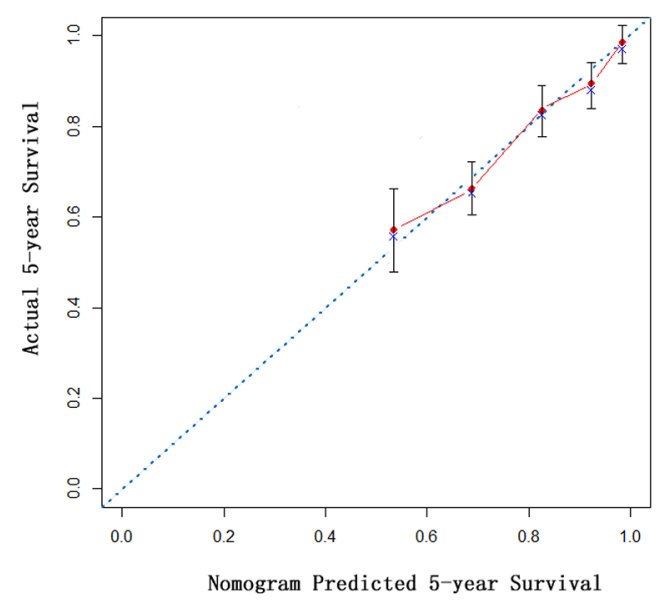

C

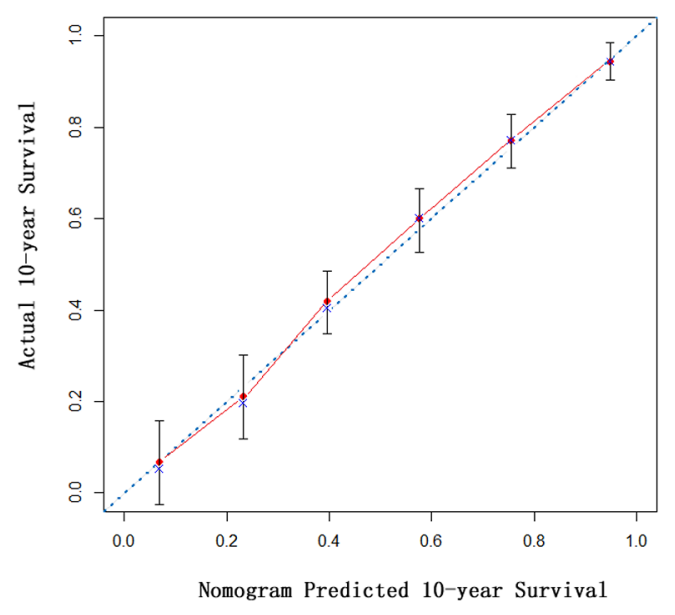

E

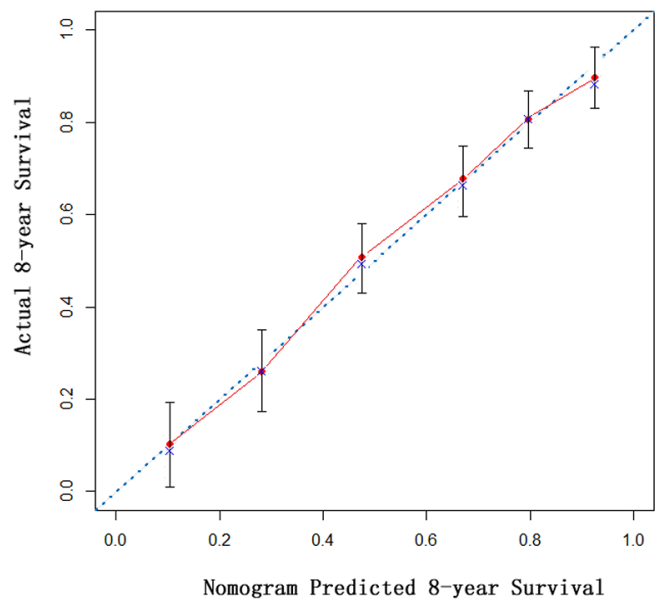

B

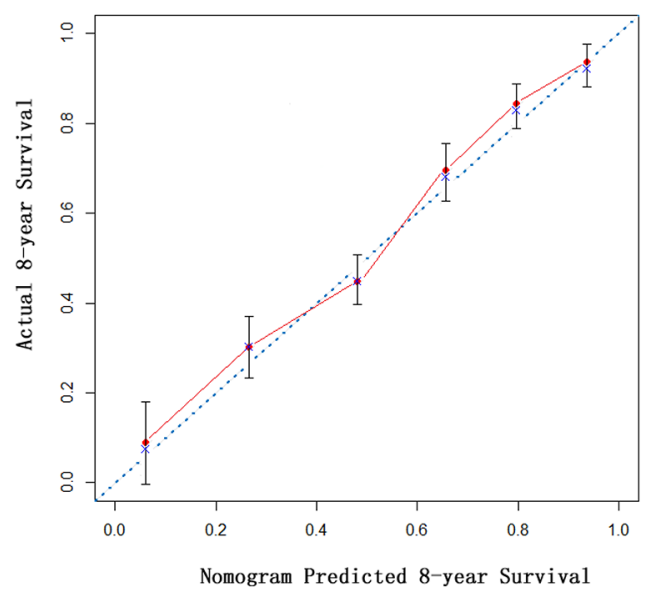

D

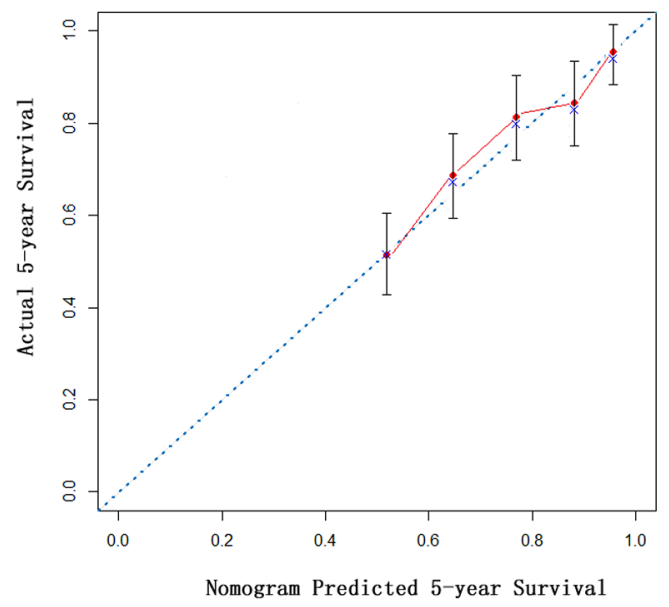

F

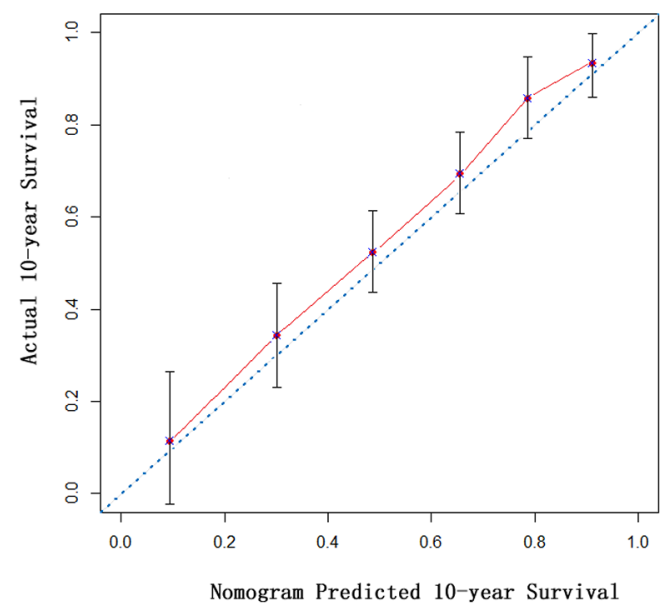

Figure 2: Calibration curve of nomogram in derivation cohort. The calibration curve for predicting patient survival at (A) 5 years, (B) 8 years and (C) 10 years in the derivation cohort and (D) 5 years, (E) 8 years and (F) 10 years in the validation cohort. Nomogram-predicted probability of overall survival is plotted on the $\mathrm{x}$-axis; actual overall survival is plotted on the $\mathrm{y}$-axis. 
Table 3: C-index of the derivation cohort

\begin{tabular}{lc}
\hline Prognosis model & C-index (95\% CI) \\
\hline Nomogram & $0.88(0.80-0.96)$ \\
Lee Grading & $0.76(0.71-0.82)$ \\
Haas Grading & $0.74(0.68-0.80)$ \\
Oxford classification & $0.78(0.68-0.87)$ \\
\hline
\end{tabular}
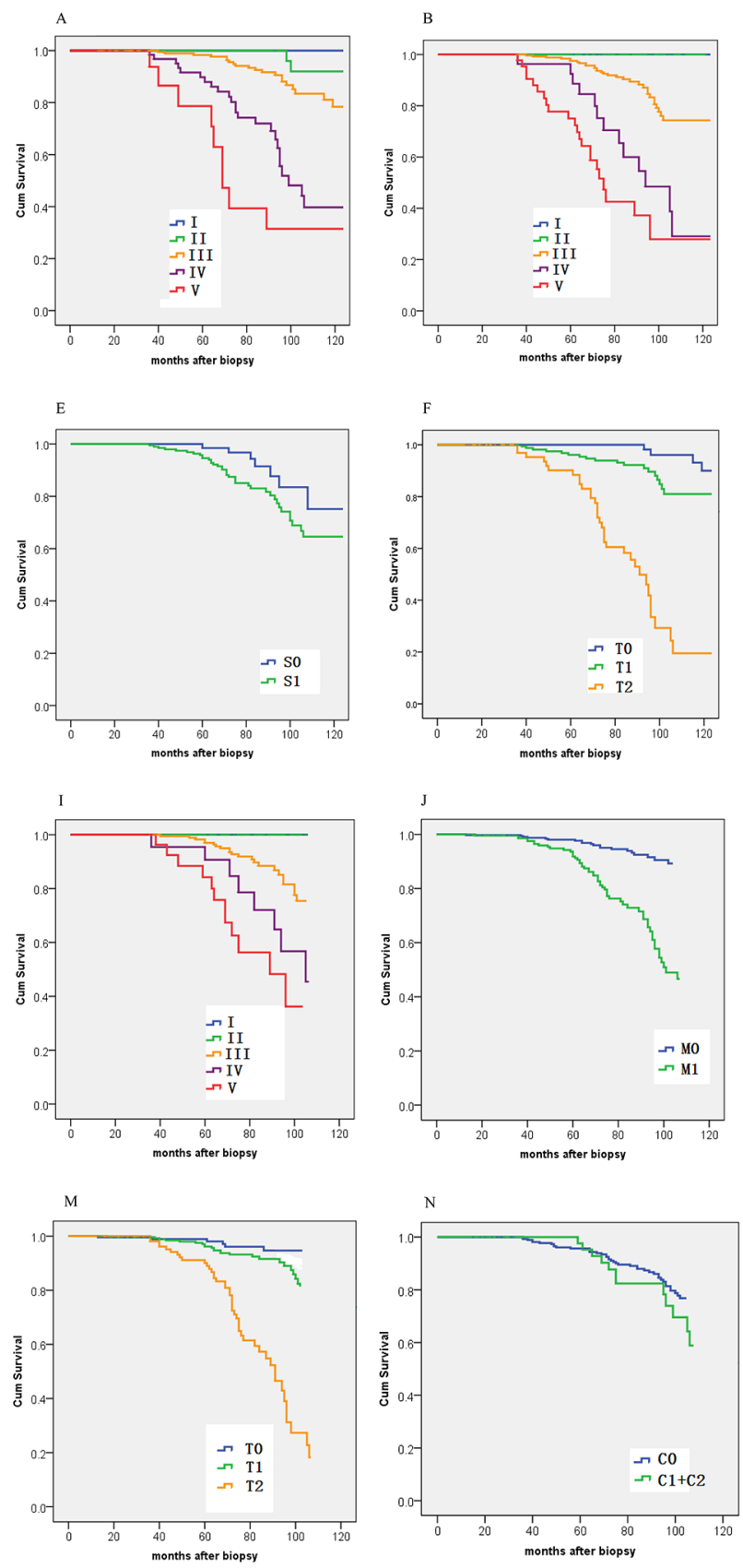
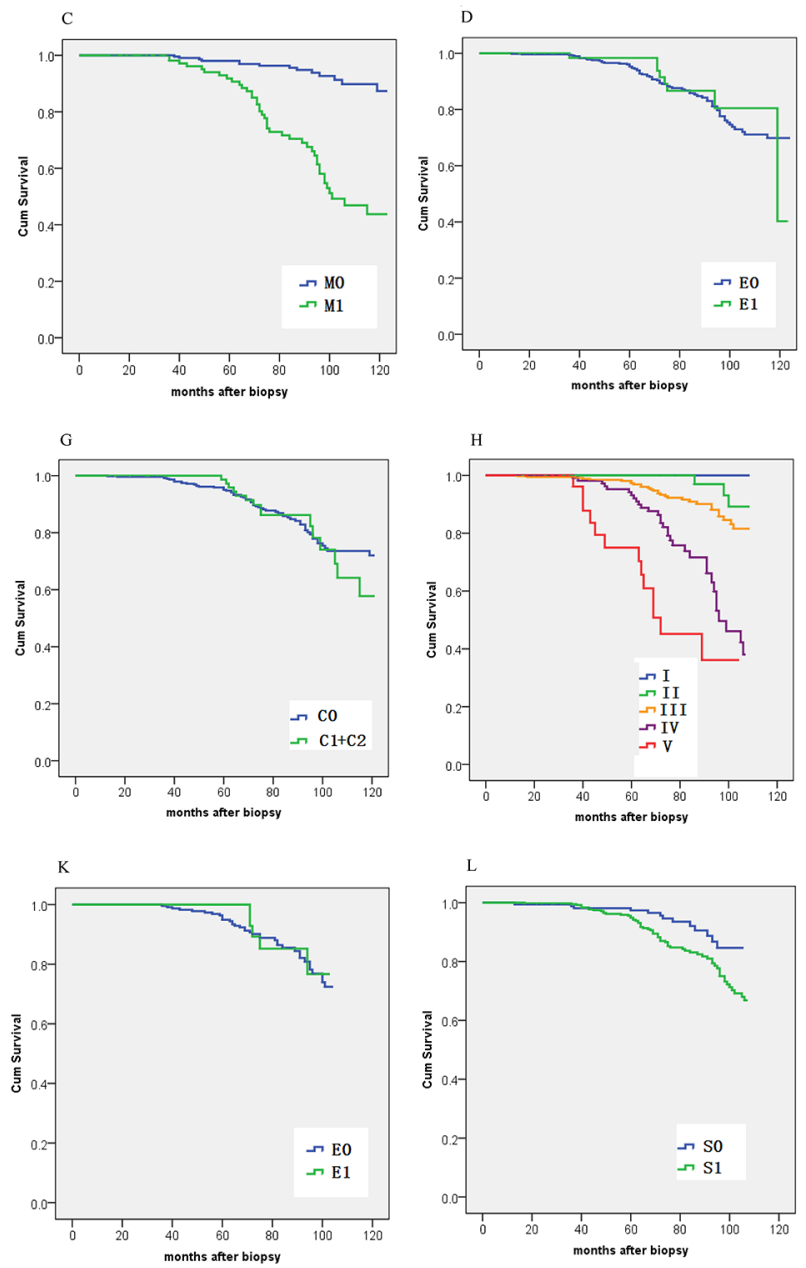

pathologic classification system, which is not generally accepted. Xie et al. developed a risk score for predicting ESRD in 619 Chinese patients who were followed for an average of 3.4 years using eGFR, systolic pressure, serum albumin, and hemoglobin [36]. However, their score has not been verified in an independent validation cohort.

Several limitations of this study should be noted. First, the nomogram was established based on data obtained from a single institution in China. The generalizability for populations of other races and other

Figure 3: Kaplan-Meier survival curves of the derivation cohort ([A] Lee grade; [B] Haas grade; [C] Oxford M; [D] Oxford E; [E] Oxford S; [F] Oxford T; [G] Oxford C) and the validation cohort ([H] Lee grade; [I] Haas grade; [J] Oxford M; [K] Oxford E; [L] Oxford S; [M] Oxford T; [N] Oxford C) categorized by different staging systems. 
Table 4: C-index of the validation cohort

\begin{tabular}{lc}
\hline Prognosis model & C-index $(\mathbf{9 5 \%} \mathbf{C I})$ \\
\hline Nomogram & $0.87(0.78-0.95)$ \\
Lee Grade & $0.77(0.70-0.83))^{*}$ \\
Hass Grade & $0.74(0.67-0.81){ }^{*}$ \\
Oxford classification & $0.79(0.70-0.88){ }^{*}$ \\
\hline${ }^{*} \mathrm{p}<0.01$ compared with nomogram.
\end{tabular}

countries may be limited. Second, patients with C2 according to the Oxford classification are too rare to have real statistical significance. The prognostic value of the crescent may be confirmed by research including more $\mathrm{C} 2$ patients. Third, patients with heavy proteinuria and advanced pathologic findings were likely to receive aggressive treatment. Both dosage and course of steroid and immunosuppressive agents is typically individualized. The effect of therapeutic intervention on the kidney prognosis needs to be confirmed by more clinical studies.

In conclusion, we have developed a nomogram that is scalable for the prognosis of IgA nephropathy and we verified its validity. This is a useful tool to estimate the individual risk for the outcome in patients with IgAN and for identifying those at high risk for future development of ESRD, which may be useful to determine the initial therapeutic strategies of patients with IgAN.

\section{MATERIALS AND METHODS}

\section{Population}

A retrospective study was conducted on a derivation cohort of patients who were diagnosed with IgAN according to a renal biopsy between January 2000 and December 2006 at The Chinese People's Liberation Army General Hospital (Beijing, China). The inclusion criteria were as follows: 1) diagnosed as IgA via renal biopsy; 2) $\geq 18$ years old; 3 ) eGFR $\geq 15 \mathrm{~mL} / \mathrm{min}$ per $1.73 \mathrm{~m}^{2}$; and 4) number of glomeruli $\geq 8$. The exclusion criteria were as follows: 1) secondary IgA nephropathy; 2) diabetes and other systemic diseases; 3) Follow-up $<36$ months; 4) Patients who underwent several rounds of renal biopsy were not repeatedly enrolled. Another validation cohort was established to confirm the effectiveness of the nomogram. From January 2007 to December 2009, an independent cohort of consecutive patients with IgAN at the same institution formed the validation cohort of this study, using the same inclusion and exclusion criteria.

\section{Clinical measures}

The sex, age, proteinuria, mean arterial pressure, and renal function were obtained from medical records. Mean arterial pressure (MAP) was defined as the diastolic pressure plus one third of the pulse pressure. An average of MAP (A-MAP) during hospitalization was calculated. Proteinuria was measured via 24-hour urine protein collection. In a similar manner to A-MAP, an average proteinuria (A-P) was calculated. Serum creatinine was measured with the enzymatic method. eGFR was calculated using the CKD-EPI formula for Asians [13]. The categorical classifications for urinary protein excretion were defined via traditional cutoffs of clinical significance [14].

\section{Pathological indicators}

The biopsy specimens of the patients were stained and observed using hematoxylin and eosin, periodic acidSchiff, periodic acid methenamine silver, and Masson's Trichrome. Pathological changes were evaluated using the Oxford classification [5]. The mesangial hypercellularity score (M) was defined as M0 if the score was $<0.5$ and as M1 if the score was $>0.5$. Endocapillary hypercellularity (E) were expressed as E0 if absent and as E1 if present. Segmental glomerulosclerosis (S) was defined as S0 if absent and as S1 if present. Tuft adhesions were regarded as $\mathrm{S} 1$ lesions. Tubular atrophy/interstitial fibrosis $(\mathrm{T})$ was semiquantitatively classified according to the percentage of the cortical area involved in the tubular atrophy/ interstitial fibrosis: T0 for $0 \%$ to $25 \%$, T1 for $26 \%$ to $50 \%$, and $\mathrm{T} 2$ for $>50 \%$. The crescent scores [15] (C) were defined as $\mathrm{C} 0$ (no cellular or fibrocellular crescents), as $\mathrm{C} 1$ (crescents in less than one fourth of all glomeruli), and $\mathrm{C} 2$ (crescents in more than one fourth of all glomeruli).

\section{Renal outcome}

The study endpoint was determined as the progression to ESRD (and ESRD was defined as GFR < $15 \mathrm{ml} / \mathrm{min}$ per $1.73 \mathrm{~m}^{2}$ ) or a decrease in eGFR $>50 \%$ [16].

\section{Statistical analyses}

Statistical analyses were performed using SPSS 22.0 (IBM Corporation, Armonk, NY, USA) and R programming software (version 3.3.3) [17]. A normaldistribution test using the Kolmogorov-Smirnov method was conducted on continuous variables and the results were expressed as the means \pm standard deviation. Data with a non-normal distribution were expressed as the median. Count data were expressed as frequency. Normally distributed data were compared using a t-test; data that was not normally distributed and ranked data were compared using the rank sum test. Count data were compared with the chi-squared test. Multivariate analyses were performed using the COX proportional hazards model with backward stepwise $[18,19]$.

A nomogram $[20,21]$ is a graphical calculating device, a two-dimensional diagram, designed to allow for approximate graphical computation of a mathematical 
function. A nomogram was formulated based on the results of multivariate analysis and by using the package of rms in R (http://www.r-project.org/). Each factor was weighted via multivariate $\mathrm{COX}$ regression coefficients [22]. The renal survival was caculated by $\mathrm{COX}$ regression equation: $\mathrm{h}(\mathrm{t}, \mathrm{x})=\mathrm{h} 0(\mathrm{t}) \exp (\beta 1 \mathrm{x} 1+\beta 2 \times 2+\cdots \cdots+\beta \mathrm{mxm})$. The predictive capacity of the model was evaluated using the concordance index (the Harrell C-Index) [23, 24] and assessed by comparing nomogram-predictions versus observed Kaplan-Meier estimates of survival probabilities [25-27]. Comparisons between the nomogram and other classification systems were performed via the $\mathrm{C}$-index with the package of Hmisc in R [28]. A larger C-index resulted in a more accurate prognostic prediction [29, 30]. During the external validation of the nomogram, the total points of each patient in the validation cohort were calculated according to the established nomogram; then, Cox regression in this cohort was performed using the total points as a factor and finally, the C-index and calibration curve were derived based on the results of regression analysis.

\section{Ethical considerations}

This study was conducted with the approval of the ethics committee of the PLA general hospital Review Board for Clinical Research. We have been approved to waive requirement for written, informed consent due to the retrospective nature of the study.

\section{Abbreviations}

A-MAP, average mean arterial pressure during hospitalization

A-P, average proteinuria during hospitalization

$\mathrm{C}$-index, concordance index

eGFR, estimate Glomerular filtration rate

ESRD, end-stage renal disease

IgAN, IgA nephropathy

\section{Author contributions}

Xiangmei Chen and Jie Wu conceived and supervised the study; Jian Liu and Shuwei Duan designed experiments; Jian Liu, Shuwei Duan and Wanjun Shen performed experiments; Jianhui Zhou provided new tools and reagents; $\mathrm{Pu}$ Chen developed new software and performed simulation studies; Li Tang and Shuwen Liu analysed data; Jian Liu and Di Wu wrote the manuscript; Guangyan Cai and Yong Wang made manuscript revisions. All authors reviewed the results and approved the final version of the manuscript.

\section{CONFLICTS OF INTEREST}

The authors declared that there were no conflicts of interest in either conducting the study or analyzing the results.

\section{FUNDING}

This work was supported by two grants from National Clinical Research Center for Kidney Disease (No. 2013BAI09B05 and No. 2015BAI12B06), and from the Science and Technology Project of Beijing, China (No. D131100004713003, No. D171100002817002).

\section{REFERENCES}

1. Maixnerova D, Reily C, Bian Q, Neprasova M, Novak J, Tesar V. Markers for the progression of IgA nephropathy. J Nephrol. 2016; 29:535-41. https://doi.org/10.1007/ s40620-016-0299-0.

2. Lee SM, Rao VM, Franklin WA, Schiffer MS, Aronson AJ, Spargo BH, Katz AI. IgA nephropathy: morphologic predictors of progressive renal disease. Hum Pathol. 1982; 13:314-22.

3. Haas M. Histologic subclassification of IgA nephropathy: a clinicopathologic study of 244 cases. Am J Kidney Dis. 1997; 29:829-42.

4. Working Group of the International IgA Nephropathy Network and the Renal Pathology Society, Roberts IS, Cook HT, Troyanov S, Alpers CE, Amore A, Barratt J, Berthoux F, Bonsib S, Bruijn JA, Cattran DC, Coppo R, D'Agati V, et al. The Oxford classification of IgA nephropathy: pathology definitions, correlations, and reproducibility. Kidney Int. 2009; 76:546-56. https://doi.org/10.1038/ki.2009.168.

5. Trimarchi H, Barratt J, Cattran DC, Cook HT, Coppo R, Haas M, Liu ZH, Roberts IS, Yuzawa Y, Zhang H, Feehally J, IgAN Classification Working Group of the International IgA Nephropathy Network and the Renal Pathology Society, Conference Participants. Oxford Classification of IgA nephropathy 2016: an update from the IgA Nephropathy Classification Working Group. Kidney Int. 2017; 91:101421. https://doi.org/10.1016/j.kint.2017.02.003.

6. Donadio JV, Bergstralh EJ, Grande JP, Rademcher DM. Proteinuria patterns and their association with subsequent end-stage renal disease in IgA nephropathy. Nephrol Dial Transplant. 2002; 17:1197-203.

7. Zhao YF, Zhu L, Liu LJ, Shi SF, Lv JC, Zhang H. Measures of Urinary Protein and Albumin in the Prediction of Progression of IgA Nephropathy. Clin J Am Soc Nephrol. 2016; 11:947-55. https://doi.org/10.2215/CJN.10150915.

8. Inker LA, Mondal H, Greene $\mathrm{T}$, Masaschi $\mathrm{T}$, Locatelli F, Schena FP, Katafuchi R, Appel GB, Maes BD, Li PK, Praga M, Del Vecchio L, Andrulli S, et al. Early Change in Urine Protein as a Surrogate End Point in Studies of IgA Nephropathy: An Individual-Patient Meta-analysis. Am J Kidney Dis. 2016; 68:392-401. https://doi.org/10.1053/j. ajkd.2016.02.042.

9. Descamps-Latscha B, Witko-Sarsat V, Nguyen-Khoa T, Nguyen AT, Gausson V, Mothu N, Cardoso C, Noel LH, Guerin AP, London GM, Jungers P. Early prediction of IgA 
nephropathy progression: proteinuria and AOPP are strong prognostic markers. Kidney Int. 2004; 66:1606-12. https:// doi.org/10.1111/j.1523-1755.2004.00926.x.

10. Knoop T, Vagane AM, Vikse BE, Svarstad E, Magnusdottir BT, Leh S, Varberg Reisaeter A, Bjorneklett R. Addition of eGFR and Age Improves the Prognostic Absolute Renal Risk-Model in 1,134 Norwegian Patients with IgA Nephropathy. Am J Nephrol. 2015; 41:210-9. https://doi. org/10.1159/000381403.

11. Lafayette RA, Canetta PA, Rovin BH, Appel GB, Novak J, Nath KA, Sethi S, Tumlin JA, Mehta K, Hogan M, Erickson $\mathrm{S}$, Julian BA, Leung N, et al. A Randomized, Controlled Trial of Rituximab in IgA Nephropathy with Proteinuria and Renal Dysfunction. J Am Soc Nephrol. 2017; 28:1306-13. https://doi.org/10.1681/ASN.2016060640.

12. Lv J, Zhang H, Zhou Y, Li G, Zou W, Wang H. Natural history of immunoglobulin A nephropathy and predictive factors of prognosis: a long-term follow up of 204 cases in China. Nephrology (Carlton). 2008; 13:242-6. https://doi. org/10.1111/j.1440-1797.2007.00898.x.

13. Stevens LA, Claybon MA, Schmid CH, Chen J, Horio M, Imai E, Nelson RG, Van Deventer M, Wang HY, Zuo L, Zhang YL, Levey AS. Evaluation of the Chronic Kidney Disease Epidemiology Collaboration equation for estimating the glomerular filtration rate in multiple ethnicities. Kidney Int. 2011; 79:555-62. https://doi. org/10.1038/ki.2010.462.

14. Levey AS, de Jong PE, Coresh J, El Nahas M, Astor BC, Matsushita K, Gansevoort RT, Kasiske BL, Eckardt KU. The definition, classification, and prognosis of chronic kidney disease: a KDIGO Controversies Conference report. Kidney Int. 2011; 80:17-28. https://doi.org/10.1038/ ki.2010.483.

15. Haas M, Verhave JC, Liu ZH, Alpers CE, Barratt J, Becker JU, Cattran D, Cook HT, Coppo R, Feehally J, Pani A, Perkowska-Ptasinska A, Roberts IS, et al. A Multicenter Study of the Predictive Value of Crescents in IgA Nephropathy. J Am Soc Nephrol. 2017; 28:691-701. https:// doi.org/10.1681/ASN.2016040433.

16. Working Group of the International IgA Nephropathy Network and the Renal Pathology Society, Cattran DC, Coppo R, Cook HT, Feehally J, Roberts IS, Troyanov S, Alpers CE, Amore A, Barratt J, Berthoux F, Bonsib $\mathrm{S}$, Bruijn JA, et al. The Oxford classification of IgA nephropathy: rationale, clinicopathological correlations, and classification. Kidney Int. 2009; 76:534-45. https://doi. org/10.1038/ki.2009.243.

17. He B, Chen R, Gao X, Ren S, Yang B, Hou J, Wang L, Yang Q, Zhou T, Zhao L, Xu C, Sun Y. Nomograms for predicting Gleason upgrading in a contemporary Chinese cohort receiving radical prostatectomy after extended prostate biopsy: development and internal validation. Oncotarget. 2016; 7:17275-85. https://doi.org/10.18632/ oncotarget. 7787 .
18. Harrell FE Jr, Lee KL, Mark DB. Multivariable prognostic models: issues in developing models, evaluating assumptions and adequacy, and measuring and reducing errors. Stat Med. 1996; 15:361-87. https://doi.org/10.1002/(SICI)10970258(19960229)15:4<361::AID-SIM168>3.0.CO;2-4.

19. Cao LL, Lu J, Lin JX, Zheng CH, Li P, Xie JW, Wang JB, Chen QY, Lin M, Tu RH, Huang CM. A novel predictive model based on preoperative blood neutrophil-tolymphocyte ratio for survival prognosis in patients with gastric neuroendocrine neoplasms. Oncotarget. 2016; 7:42045-58. https://doi.org/10.18632/oncotarget.9805.

20. Lubsen J, Pool J, van der Does E. A practical device for the application of a diagnostic or prognostic function. Methods Inf Med. 1978; 17:127-9.

21. Cheng D, Qiu X, Zhuang M, Zhu C, Zou H, Zhang A. Development and validation of nomogram based on miR203 and clinicopathological characteristics predicting survival after neoadjuvant chemotherapy and surgery for patients with non-metastatic osteosarcoma. Oncotarget. 2017 Jun 16. https://doi.org/10.18632/oncotarget.18534. [Epub ahead of print].

22. Liu J, Su M, Hong S, Gao H, Zheng X, Wang S. Nomogram predicts survival benefit from preoperative radiotherapy for non-metastatic breast cancer: A SEER-based study. Oncotarget. 2017; 8:49861-8. https://doi.org/10.18632/ oncotarget.17991.

23. Tangri N, Stevens LA, Griffith J, Tighiouart H, Djurdjev O, Naimark D, Levin A, Levey AS. A predictive model for progression of chronic kidney disease to kidney failure. JAMA. 2011; 305:1553-9. https://doi.org/10.1001/ jama.2011.451.

24. Zhang B, Yuan Z, Zhao L, Pang Q, Wang P. Nomograms for predicting progression and efficacy of post-operation radiotherapy in IIIA-pN2 non-small cell lung cancer patients. Oncotarget. 2017; 8:37208-16. https://doi. org/10.18632/oncotarget.16564.

25. Wang ZX, Li GX, Zhou ZW, Huang ZP, Wang F, Xu $\mathrm{RH}$. Validation of a nomogram for selecting patients for chemotherapy after D2 gastrectomy for cancer. Br J Surg. 2017. https://doi.org/10.1002/bjs. 10550.

26. Ju J, Wang J, Ma C, Li Y, Zhao Z, Gao T, Ni Q, Sun M. Nomograms predicting long-term overall survival and cancer-specific survival in head and neck squamous cell carcinoma patients. Oncotarget. 2016; 7:51059-68. https:// doi.org/10.18632/oncotarget.10595.

27. Zeng Q, Hong MH, Shen LJ, Meng XQ, Guo X, Qian CN, Wu PH, Huang PY. Nomograms for predicting long-term survival in patients with non-metastatic nasopharyngeal carcinoma in an endemic area. Oncotarget. 2016; 7:2970819. https://doi.org/10.18632/oncotarget.8823.

28. Sun W, Jiang YZ, Liu YR, Ma D, Shao ZM. Nomograms to estimate long-term overall survival and breast cancer-specific survival of patients with luminal breast cancer. Oncotarget. 2016; 7:20496-506. https://doi.org/10.18632/oncotarget.7975. 
29. Jiang H, Tang E, Xu D, Chen Y, Zhang Y, Tang M, Xiao Y, Zhang Z, Deng X, Li H, Lin M. Development and validation of nomograms for predicting survival in patients with non-metastatic colorectal cancer. Oncotarget. 2017; 8:29857-64. https://doi.org/10.18632/ oncotarget. 16167.

30. Shi X, Hu WP, Ji QH. Development of comprehensive nomograms for evaluating overall and cancer-specific survival of laryngeal squamous cell carcinoma patients treated with neck dissection. Oncotarget. 2017; 8:29722-40. https://doi.org/10.18632/oncotarget.15414.

31. Zeng $\mathrm{CH}$, Le W, Ni Z, Zhang M, Miao L, Luo P, Wang R, Lv Z, Chen J, Tian J, Chen N, Pan X, Fu P, et al. A multicenter application and evaluation of the oxford classification of $\operatorname{IgA}$ nephropathy in adult chinese patients. Am J Kidney Dis. 2012; 60:812-20. https://doi. org/10.1053/j.ajkd.2012.06.011.

32. Coppo R, Troyanov S, Bellur S, Cattran D, Cook HT, Feehally J, Roberts IS, Morando L, Camilla R, Tesar V, Lunberg S, Gesualdo L, Emma F, et al. Validation of the Oxford classification of IgA nephropathy in cohorts with different presentations and treatments. Kidney Int. 2014; 86:828-36. https://doi.org/10.1038/ki.2014.63.

33. Fang J, Li W, Li D, Tan Z. Baseline proteinuria, urinary osmotic pressure, and renal function as positive predictors of corticosteroids plus cyclophosphamide treatment efficacy in IgA nephropathy. Chin Med J (Engl). 2014; 127:1710-4.

34. Okonogi H, Utsunomiya Y, Miyazaki Y, Koike K, Hirano K, Tsuboi N, Suzuki T, Hara Y, Ogura M, Hosoya T, Kawamura T. A predictive clinical grading system for immunoglobulin A nephropathy by combining proteinuria and estimated glomerular filtration rate. Nephron Clin Pract. 2011; 118:c292-300. https://doi.org/10.1159/000322613.

35. Berthoux F, Mohey H, Laurent B, Mariat C, Afiani A, Thibaudin L. Predicting the risk for dialysis or death in IgA nephropathy. J Am Soc Nephrol. 2011; 22:752-61. https:// doi.org/10.1681/ASN.2010040355.

36. Xie J, Kiryluk K, Wang W, Wang Z, Guo S, Shen P, Ren H, Pan X, Chen X, Zhang W, Li X, Shi H, Li Y, et al. Predicting progression of IgA nephropathy: new clinical progression risk score. PLoS One. 2012; 7:e38904. https:// doi.org/10.1371/journal.pone.0038904. 